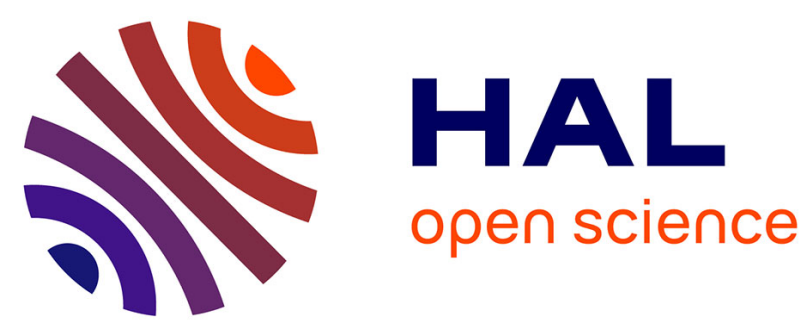

\title{
Mid-infrared two-octave spanning supercontinuum generation in a Ge-Se-Te glass suspended core fiber
} Arnaud Lemiere, Frédéric Desevedavy, Bertrand Kibler, Pierre Mathey, Grégory Gadret, Jean-Charles Jules, Christophe Aquilina, Pierre Béjot, Franck Billard, Olivier Faucher, et al.

\section{To cite this version:}

Arnaud Lemiere, Frédéric Desevedavy, Bertrand Kibler, Pierre Mathey, Grégory Gadret, et al.. Midinfrared two-octave spanning supercontinuum generation in a Ge-Se-Te glass suspended core fiber. Laser Physics Letters, 2019, 16 (7), pp.075402. 10.1088/1612-202X/ab2053 . hal-02389043

\section{HAL Id: hal-02389043 https://hal.science/hal-02389043}

Submitted on 6 Dec 2019

HAL is a multi-disciplinary open access archive for the deposit and dissemination of scientific research documents, whether they are published or not. The documents may come from teaching and research institutions in France or abroad, or from public or private research centers.
L'archive ouverte pluridisciplinaire $\mathbf{H A L}$, est destinée au dépôt et à la diffusion de documents scientifiques de niveau recherche, publiés ou non, émanant des établissements d'enseignement et de recherche français ou étrangers, des laboratoires publics ou privés. 


\title{
Mid-infrared two-octave spanning
}

\section{supercontinuum generation in a Ge-Se-Te glass suspended core fiber}

\author{
Arnaud Lemière ${ }^{1}$, Frédéric Désévédavy ${ }^{1}$, Bertrand Kibler ${ }^{1}$, Pierre Mathey ${ }^{1}$, Grégory \\ Gadret $^{1}$, Jean-Charles Jules ${ }^{1}$, Christophe Aquilina ${ }^{1}$, Pierre Béjot ${ }^{1}$, Franck Billard ${ }^{1}$, \\ Olivier Faucher ${ }^{1}$, and Frédéric Smektala ${ }^{1}$ \\ ${ }^{1}$ Laboratoire Interdisciplinaire Carnot de Bourgogne (ICB), UMR6303 CNRS-Université Bourgogne \\ Franche-Comté, Avenue Alain Savary, 21000 Dijon, France \\ E-mail: bertrand.kibler@u-bourgogne.fr
}

Received xxxxxx

Accepted for publication $\mathrm{xxxxxx}$

Published xxxxxx

\begin{abstract}
We report on both the fabrication and the application of a Ge-Se-Te glass-based suspended core fiber for mid-infrared supercontinuum generation. A two-octave spanning mid-infrared light source (from 3.25 to $13 \mu \mathrm{m}$ ) is experimentally demonstrated by pumping the chalcogenide fiber with sub-100 fs pulses at $8.6 \mu \mathrm{m}$. Numerical simulations of nonlinear pulse propagation as well as fiber properties are also provided and support experimental measurements.
\end{abstract}

Keywords: chalcogenide glasses, optical fibers, supercontinuum generation, mid-infrared optics

\section{Introduction}

Many chemical species, as organic compounds and biomolecules, present fundamental vibrational resonances between 2 and $20 \mu \mathrm{m}$. The mid-infrared (mid-IR) spectral region is thus considered as a fingerprint region of huge interest for sensing applications [1],[2]. Particularly, greenhouse pollutants gases, such as $\mathrm{CH}_{4}, \mathrm{CO}_{2}, \mathrm{NH}_{3}$, and $\mathrm{NO}_{\mathrm{x}}$, present absorption bands in this spectral region [1],[2]. Current issues related with air quality and climatic modifications drive [3] the interest for developing new sensing devices. Coherent tuneable large band sources emitting in this spectral region are promising for such applications.

Over the past decade chalcogenide-glass based optical fibers have revolutionized the field of mid-IR broadband light sources [4][5][6]. Chalcogenide glasses exhibit the suitable wide transparency window and high optical nonlinearity [7], making them the best candidates for midinfrared supercontinuum (SC) generation. Numerous achievements have been accomplished through the development of different kinds of fiber structures, such as step-index, microstructured and tapered fibers, in order to control light guidance according to the pumping conditions. In particular, the advanced methods of microstructured or suspended-core fibers and fiber tapering have been widely used to decrease zero dispersion wavelengths (ZDWs) while enabling enhanced effective nonlinearities. As a result, efficient mid-IR SC generation can be investigated by using relatively shorter pump wavelengths with lower pump powers, thus fitting the current needs of developing compact devices based on fiber laser pumps below $5 \mu \mathrm{m}$ [8]. However, it is worth mentioning that the broadest SC spectra have been obtained in step-index fibers with larger transmission window (i.e., more robust and less sensitive to 
aging issues [9]) and by using longer pumping wavelengths delivered by high-energy optical parametric amplifiers

Table 1. Recent survey on mid-IR SC generation in various configurations of chalcogenide fibers

\begin{tabular}{|c|c|c|c|}
\hline Fiber Composition (core/clad) & Spectral Coverage $(\mu \mathrm{m})$ & $\begin{array}{l}\text { Pump Wavelength } \\
(\mu \mathrm{m})\end{array}$ & Year \\
\hline \multicolumn{4}{|c|}{ As-S suspended-core or tapered fibers } \\
\hline $\mathrm{As}_{2} \mathrm{~S}_{3} / \mathrm{As}_{2} \mathrm{Se}_{3}$ & $1.4-7.2$ & 3.25 & $2017[11]$ \\
\hline $\mathrm{As}_{2} \mathrm{~S}_{3}$ & $1.0-4.8$ & 3.0 & 2018 [12] \\
\hline $\mathrm{As}_{2} \mathrm{~S}_{3} / \mathrm{Ge}_{20} \mathrm{As}_{20} \mathrm{Se}_{15} \mathrm{Te}_{45}$ & 2.1-7.0 & 4.5 & $2018[13]$ \\
\hline $\mathrm{As}_{2} \mathrm{~S}_{3} / \mathrm{Ge}_{15} \mathrm{Sb}_{10} \mathrm{Se}_{75}$ & $1.5-9.5$ & 3.0 & $2018[14]$ \\
\hline $\mathrm{As}_{2} \mathrm{~S}_{3} / \mathrm{As}_{38} \mathrm{~S}_{62}$ & $1.5-8.3$ & 3.75 & 2018 [15] \\
\hline \multicolumn{4}{|c|}{ As-Se suspended-core fibers } \\
\hline $\mathrm{AsSe}_{2} / \mathrm{As}_{2} \mathrm{~S}_{5}$ & $1.3-5.4$ & 3.39 & 2014 [16] \\
\hline $\mathrm{As}_{38} \mathrm{Se}_{62}$ & $1.7-7.5$ & 4.4 & 2015 [17] \\
\hline $\mathrm{As}_{2} \mathrm{Se}_{3}$ & $2.8-7.1$ & ZBLAN Cascade & $2016[18]$ \\
\hline \multicolumn{4}{|c|}{ Other glass-system suspended-core fibers } \\
\hline $\mathrm{Ge}_{20} \mathrm{As}_{20} \mathrm{Se}_{15} \mathrm{Te}_{45} / \mathrm{Ge}_{20} \mathrm{Sb}_{5} \mathrm{Se}_{75}$ & $1.7-11.3$ & 5 & 2018 [19] \\
\hline $\mathrm{Ge}_{20} \mathrm{Se}_{60} \mathrm{Te}_{20}$ & $2.0-11.5$ & 5.5 & $2019[20]$ \\
\hline \multicolumn{4}{|c|}{ As-Se step-index fibers } \\
\hline $\mathrm{As}_{40} \mathrm{Se}_{60} / \mathrm{Ge}_{10} \mathrm{As}_{23.4} \mathrm{Se}_{66.6}$ & $1.4-13.3$ & 6.3 & $2014[10]$ \\
\hline $\mathrm{As}_{2} \mathrm{Se}_{3} / \mathrm{AsSe}_{2}$ & $2.0-15.1$ & 9.8 & $2016[21]$ \\
\hline $\mathrm{As}_{2} \mathrm{Se}_{3} / \mathrm{As}_{2} \mathrm{~S}_{3}$ & $2.0-12.0$ & 3 & $2017[22]$ \\
\hline \multicolumn{4}{|c|}{ Other glass-system step-index fibers } \\
\hline $\mathrm{Ge}_{20} \mathrm{As}_{20} \mathrm{Se}_{15} \mathrm{Te}_{45} / \mathrm{Ge}_{20} \mathrm{As}_{20} \mathrm{Se}_{17} \mathrm{Te}_{43}$ & $1.5-14.0$ & 4.5 & $2016[23]$ \\
\hline $\begin{array}{c}\left(\mathrm{Ge}_{10} \mathrm{Te}_{43}\right)_{90}-\mathrm{AgI}_{10} /\left(\mathrm{Ge}_{10} \mathrm{Te}_{40}\right)_{90}-\mathrm{AgI}_{10} \\
/ \mathrm{Ge}_{10} \mathrm{Sb}_{10} \mathrm{Se}_{80}\end{array}$ & $2.0-16.0$ & 7 & 2017 [1] \\
\hline $\begin{aligned} \mathrm{Ge}_{20} \mathrm{As}_{20} \mathrm{Se}_{15} \mathrm{Te}_{45} / \mathrm{Ge}_{19} \mathrm{As}_{16} \mathrm{Se}_{25} \mathrm{Te}_{40} / \mathrm{Ge}_{20} \mathrm{As} \\
\mathrm{Se}_{17} \mathrm{Te}_{43}\end{aligned}$ & $2.0-14.0$ & 5 & 2019 [24] \\
\hline $\mathrm{Ge}_{20} \mathrm{Se}_{60} \mathrm{Te}_{20} / \mathrm{Ge}_{20} \mathrm{Se}_{70} \mathrm{Te}_{10}$ & $2.0-14.0$ & 7.7 & 2019 [20] \\
\hline
\end{tabular}

operating in the femtosecond regime. Table 1 presents a survey of mid-IR SC spectra obtained in chalcogenide fibers made of distinct glass compositions and index profiles since the ultrabroadband mid-IR SC generated in a step-index fiber by Petersen et al. in 2014 [10]. From Table 1, it clearly appears that, to the best of our knowledge, the broadest SC obtained with As-S or As-Se suspended-core fibers ends up to $9.5 \mu \mathrm{m}$. A way to allow further mid-IR spectral broadening is to modify the glass system and its transmission window. Another solution is the control of the fiber geometry to manage the group-velocity dispersion. By combining these two features, a suspended-core fiber consisting of dual chalcogenide glasses (Ge-As-Se-Te / Ge-Sb-Se) has been developed, leading to the largest SC obtained in a chalcogenide suspended-core fiber, covering the $1.7-11.3 \mu \mathrm{m}$ spectral region with a pumping wavelength around $5 \mu \mathrm{m}$ [19]. However, one can note again that step-index fibers based on a similar glass system allow to obtain a larger SC span [23].

Most of glass systems listed in Table 1 contain arsenic as well as antimony which are toxic elements. Especially, they lead to carcinogen oxides when they are exposed to atmosphere [25]. The European REACH (Registration, Evaluation, Authorization and Restriction of Chemicals) [26] regulation aims to limit as far as possible the use of highly toxic substances, and this drives the interest to search for As and Sb-free chalcogenide glasses. From that point of view, the GST (Ge-Se-Te) glass system is an alternative for nonlinear applications in the mid-IR region. GST glass system is known from 1966 [27], but it has been less studied for SC applications though its transmission window is similar to the As-Se glass [20][21], mainly because the glass formation and fibre drawing is more tricky. Maurugeon et al. successfully drew a Te-rich GST fiber and then performed sensing application between 13 and $16 \mu \mathrm{m}$ where $\mathrm{CO}_{2}$ absorbs with the Fiber Evanescent Waves Spectroscopy method [28]. The composition used contains only of a few percent of Se to minimize absorption between 16-18 $\mu \mathrm{m}$ and presents a minimum of losses of $10 \mathrm{~dB} / \mathrm{m}$ at $10.5 \mu \mathrm{m}$. The dependence of the refractive index with respect to distinct compositions of GST glasses was investigated in Ref. [29]. The control of Te and Se contents (i.e., from Se-rich to Terich) in the glass system allow to change the resulting refractive index over the range 2.5-3.4 in the mid-IR. In 2015 , Jiang et al. proposed a purification process to obtain a low-loss Se-rich Ge-Se-Te chalcogenide fiber $\left(\mathrm{Ge}_{20} \mathrm{Se}_{70} \mathrm{Te}_{10}\right)$ [30]. The optical loss was found to be $1.4 \mathrm{~dB} / \mathrm{m}$ at $4.2 \mu \mathrm{m}$ and less than $3 \mathrm{~dB} / \mathrm{m}$ between 1.5 and $6.3 \mu \mathrm{m}$. Recently, Sun et al. has synthesized Ge-Se-Te glasses and also studied the evolution of the nonlinear index $n_{2}$ as a function of the Te content [31]. It appears that $\mathrm{n}_{2}$ increases with Te content. Based on this potential of Se-rich GST glass system, we have 
recently demonstrated the fabrication of optical fibers with distinct index profiles, namely, single-material fibers with or without a suspended core and standard step-index fibers with varying core diameter [20]. In addition, we have evidenced their potential for nonlinear mid-IR devices by means of SC generation spanning from 2 to $14 \mu \mathrm{m}$ in a step-index profile [20]. In the same work, a preliminary study of suspendedcore fibers is also presented with a SC generation experiment spanning from 2 to $11.5 \mu \mathrm{m}$. This result then compete with the state-of-the-art of SC in suspended-core fibers shown in Table 1 .

In the present work, our purpose is to present in more detail the development of As-Sb-free chalcogenide suspended core fibers based on the ternary glass system $\mathrm{Ge}$ Se-Te. In particular, the glass composition $\mathrm{Ge}_{20} \mathrm{Se}_{70} \mathrm{Te}_{10}$ is here successfully synthesized, partially purified and drawn to a suspended core fiber. The core optical transmission is measured whereas group-velocity dispersion and light confinement properties are computed and discussed. Finally, to the best of our knowledge, we report on the largest mid-IR extension of SC generation in a suspended-core optical fiber. More specifically, we demonstrate a SC spanning from 3.25 to $13 \mu \mathrm{m}$ into a $12-\mu \mathrm{m}$ suspended-core fiber pumped by sub$100-f s$ pulses at $8.6 \mu \mathrm{m}$. Experimental SC results are supported by numerical simulations of the nonlinear pulse propagation.

\section{Glass synthesis, fiber fabrication and characterization}

A $\mathrm{Ge}_{20} \mathrm{Se}_{70} \mathrm{Te}_{10}$ glass preform is synthesized by the standard melt quenching method [32]. High purity elements of $5 \mathrm{~N}$ bulky Ge and Te from Umicore and $5 \mathrm{~N}$ Se pellets from Alfa Aesar are used. Stoichiometric quantities are weighted and then inserted into a silica ampoule. In this case we performed a slight purification: this ampoule is evacuated at $1.10^{-5} \mathrm{mbar}$ for several hours. Then we proceed to a single static distillation (see Fig.1). This allows removing of refractory elements, such as Carbon or $\mathrm{SiO}_{2}$ responsible for optical scattering [33][34]. Finally, the ampoule is sealed and inserted in a rocking furnace for glass synthesis (see Fig. 1). The batch is heated up to $850^{\circ} \mathrm{C}$ for 10 hours to allow reaction between the starting products, then the melt is quenched in water at ambient temperature and finally annealed at $\mathrm{T}_{\mathrm{g}}-5^{\circ} \mathrm{C}$ for 12 hours.

The GST glass transmission is measured on a $4.7 \mathrm{~mm}-$ thick bulk sample, previously polished with $\mathrm{SiC}$ papers and diamond suspensions. Mid-IR transmission is measured with a Fourier Transform InfraRed (FTIR) Perkin Elmer spectrometer (Spectrum One). Transmission in the near-IR region is measured with a Perkin Elmer Lambda 900 spectrometer. The transmission $T$ of the glass is presented in
Figure 2. Multi-phonon absorption is measured around 17 $\mu \mathrm{m}$.
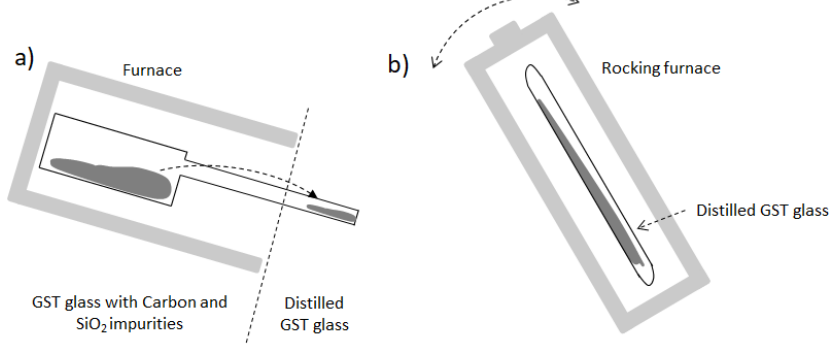

Figure 1. Illustration of (a) distillation under static vacuum and (b) refining step in the rocking furnace.

The bandgap is measured at around $1 \mu \mathrm{m}$ which corresponds to an absorption coefficient of $10 \mathrm{~cm}^{-1}$. We can express the absorption coefficient with the following equation:

$$
\alpha=\frac{1}{L} \ln \left(\frac{1}{T}\right) \text { with } T=\frac{I}{I_{0}}
$$

where $I$ (resp. $I_{0}$ ) is the output (resp. input) intensity of the light and $\mathrm{L}$ the thickness of the bulk.

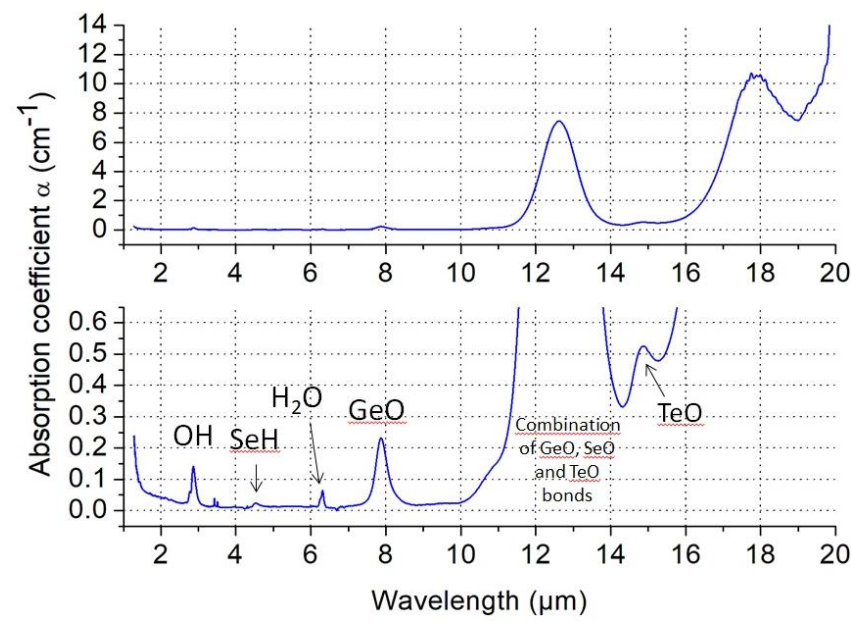

Figure 2. Absorption coefficient of GST glass. The bottom graph is a zoom on the vertical axis for a better observation of absorption bands.

Our slight purification process allows to decrease extrinsic absorption bands but not to entirely remove them: especially $\mathrm{OH}, \mathrm{H}_{2} \mathrm{O}$, Se-H, Ge-O, Te-O and Se-O bonds vibration bands are still visible [30][31][35]. However, absorption coefficient due to impurities between 2 and $10 \mu \mathrm{m}$ are smaller than $0.3 \mathrm{~cm}^{-1}$ which is low enough for nonlinear experiments on short fiber length, see part 4. The absorption due to Se-O, Ge-O and Te-O bonds related with the band centred at $12.7 \mu \mathrm{m}$ corresponds to an absorption coefficient of $7.5 \mathrm{~cm}^{-1}$. This value is lower than recent work considering a non-purified glass [30]. Table 2 lists the distinct absorption bands measured in our glass. 
Table 2. Intensity and position of absorption bands compared to the literature

\begin{tabular}{|c|c|c|c|c|c|c|}
\hline $\begin{array}{c}\text { Chemical } \\
\text { species }\end{array}$ & $\lambda(\mu \mathrm{m})$ & $\alpha\left(\mathrm{cm}^{-1}\right)$ & $\alpha(\mathrm{dB} / \mathrm{m})$ & $\varepsilon(\mathrm{dB} / \mathrm{m} / \mathrm{ppm})$ & Content $(\mathrm{ppm})$ & $\begin{array}{c}\text { Comparison with } \\
\text { literature }\end{array}$ \\
\hline $\mathrm{Se}-\mathrm{H}$ & 4.25 & 0.025 & 10.7 & $1[33][36]$ & $10.65 \mathrm{ppm}(\mathrm{at})$ & {$[20][33][34][37]$} \\
\hline $\mathrm{OH}$ & 2.9 & 0.141 & 60.7 & $10[38]$ & $6.11 \mathrm{ppm}(\mathrm{wt})$ & {$[20][32][34][37]$} \\
\hline $\mathrm{Ge}-\mathrm{O}$ & 7.9 & 0.232 & 100.7 & - & - & {$[20][35]$} \\
\hline $\mathrm{Te}-\mathrm{O}$ & 15 & 0.525 & 228.0 & - & - & {$[20]$} \\
\hline $\mathrm{H}_{2} \mathrm{O}$ & 6.3 & 0.065 & 28.2 & - & - & {$[20][37]$} \\
\hline
\end{tabular}

Assuming Se-H extinction coefficient $\varepsilon_{S e H}=1 \mathrm{~dB} / \mathrm{m} / \mathrm{ppm}$ (at) [33][36], we estimate the residual $\mathrm{Se}-\mathrm{H}$ quantity at 10 $\operatorname{ppm}($ at) which is of the same order of magnitude as previous studies [20][33][34][37]. In the case of $\mathrm{OH}$ related absorption band, $\mathrm{OH}$ extinction coefficient is measured in silica as $\varepsilon_{O H}=10 \mathrm{~dB} / \mathrm{m} / \mathrm{ppm}(\mathrm{wt})$ [38] and by considering such a value, there is $6 \mathrm{ppm}(\mathrm{wt})$ of $\mathrm{OH}$ in our fiber. This value, above that of previous works [20][34][37], is related to the fact that we only performed a static distillation for the synthesis of our glass, and not a whole purification procedure with various dynamic and static distillation steps [19] [32]. These considerations stands also for $\mathrm{Ge}-\mathrm{O}$ and $\mathrm{H}_{2} \mathrm{O}$ absorptions [20][35][37].

Next, a suspended-core fiber is fabricated from the mechanical drilling of a $16 \mathrm{~mm}$ outer diameter initial rod [39]. Three holes are drilled with $1 \mathrm{~mm}$ in diameter and 30 $\mathrm{mm}$ in length. During the drawing process, these holes allow the formation of the air-suspended structure with three fine bridges supporting the core. The drilled preform is indeed drawn to a fiber under a nitrogen gas pressure (1-4 mbar) to control the hole's size as described in the work of Savelii et al. [40]. The drawing process is occurring at a temperature, inside the furnace, of around $380{ }^{\circ} \mathrm{C}$. Several meters of fiber with a suspended-core diameter $\Phi=12 \mu \mathrm{m}$ are obtained from a $6 \mathrm{~cm}$-long preform (see Fig. 3).

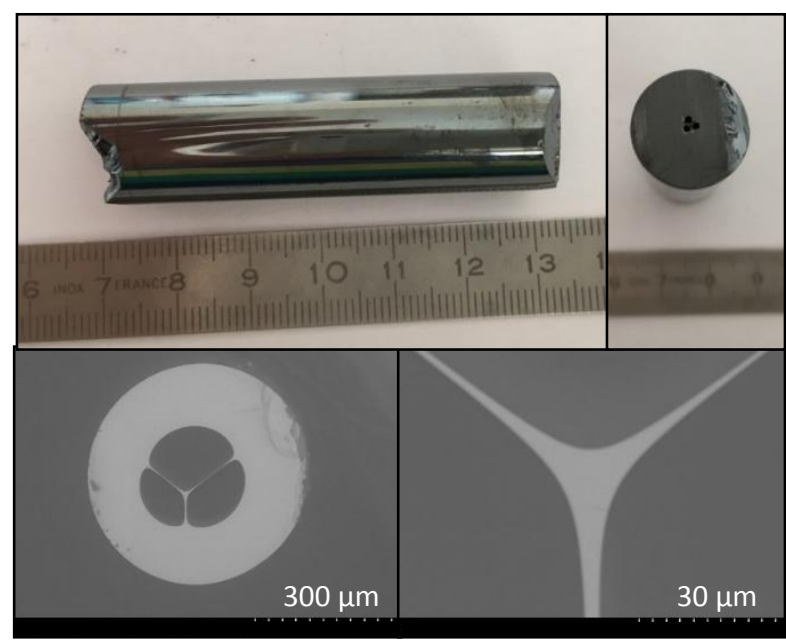

Figure 3. Pictures of the drilled preform (upper left) and the transverse profile (upper right) of the fiber preform. Lower part, scanning electron microscope images of the air-suspended structure with a $12-\mu \mathrm{m}$ core.

The refractive index of the glass was calculated using Clausius-Mossoti relation and the refractive index measurements of binary systems $\mathrm{GeSe}_{4}$ and $\mathrm{GeTe}_{4}$ found in the literature [41][42]. The refractive indices based on bulk reflection measurement curves [29] are not accurate enough for numerical simulations. Here we consider our ternary $\mathrm{Ge}_{20} \mathrm{Se}_{70} \mathrm{Te}_{10}$ glass as a glass obtained from the addition of $0.875 \mathrm{GeSe}_{4}$ and $0.175 \mathrm{GeTe}_{4}$ [20]. The wavelength dependence of refractive index is plotted in Fig. 4. It is well fitted with a two-pole Sellmeier equation (Eq. 2) and the corresponding Sellmeier coefficients are listed in Table 3.

$$
n^{2}=1+\sum_{i=1}^{2} \frac{A_{i} \lambda^{2}}{\lambda^{2}-\lambda_{i}^{2}}
$$

Table 3. Sellmeier coefficients for $\mathrm{GeSe}_{4}, \mathrm{GeTe}_{4}$ and $\mathrm{Ge}_{20} \mathrm{Se}_{70} \mathrm{Te}_{10}$

\begin{tabular}{lcccc}
\hline $\begin{array}{l}\text { Glass } \\
\text { composition }\end{array}$ & $\mathbf{A}_{\mathbf{1}}$ & $\mathbf{A}_{\mathbf{2}}$ & $\boldsymbol{\lambda}_{\mathbf{1}}(\boldsymbol{\mu \mathbf { m } )}$ & $\boldsymbol{\lambda}_{\mathbf{2}}(\boldsymbol{\mu} \mathbf{m})$ \\
\hline $\mathrm{GeSe}_{4}$ & 4.813 & 0.126 & 0.278 & 19.738 \\
$\mathrm{GeTe}_{4}$ & 9.943 & 0.318 & 0.522 & 18.298 \\
$\mathrm{Ge}_{20} \mathrm{Se}_{70} \mathrm{Te}_{10}$ & 5.225 & 0.202 & 0.298 & 21.606 \\
\hline
\end{tabular}

Group-velocity dispersion and effective mode area of the fundamental mode of the suspended-core fiber are then investigated through numerical simulations based on the fiber geometry derived from the scanning electron microscopy image and by means of a commercial software using a vectorial beam propagation method (RSoft product). Figure $4 \mathrm{a}$ shows the wavelength dependence of the dispersion for the fundamental guided mode, for distinct core diameters, as well as the dispersion of the bulk glass. The strong light confinement allowed by the suspended core geometry allows to tune the zero dispersion wavelength (ZDW) well below the intrinsic ZDW of the bulk material located at $6.6 \mu \mathrm{m}$. In the present study we focus on a $12 \mu \mathrm{m}$ diameter suspended-core fiber; this large core fiber exhibits a single $\mathrm{ZDW}$ at $4.6 \mu \mathrm{m}$, it also avoids significant light coupling issues in the mid-IR region. One can note that in the case of the simple step-index fiber profile studied in Ref. [20], the effect of the core dimension on the dispersion 
profile is quite different and the $\mathrm{ZDW}$, when it exists, remains located beyond $5.5 \mu \mathrm{m}$ whatever the core diameter.
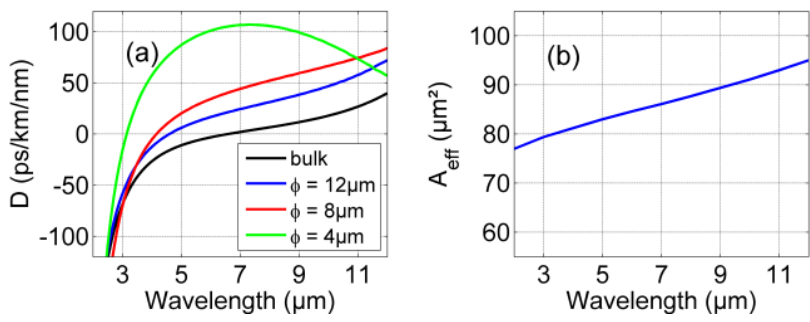

Figure 4. (a) Calculated wavelength-dependent dispersion $D$ of the fundamental guided mode in suspended-core fibers with distinct core diameters $\phi=4,8$, and $12 \mu \mathrm{m}$. The solid black line indicates the bulk dispersion of the glass $\left(\mathrm{Ge}_{20} \mathrm{Se}_{70} \mathrm{Te}_{10}\right)$. (b) Calculated wavelength-dependent effective mode area of the fundamental guided mode in the $12 \mu \mathrm{m}$-suspended-core fiber.

The calculated evolution of the effective mode area of our suspended-core fiber is shown in Fig. 4b. In particular, we denote a rather constant confinement of the fundamental guided mode over the large mid-IR wavelength region under study. In the following, we consider the nonlinear coefficient $n_{2}=8 \times 10^{-18} \mathrm{~m}^{2} \mathrm{~W}^{-1}$ corresponding to an average of values reported in Refs. [31][43]; thus the effective nonlinear parameter of our suspended core fiber at $8 \mu \mathrm{m}$ is found to be $\gamma \sim 0.07 \mathrm{~W}^{-1} \mathrm{~m}^{-1}$

\section{Experimental configuration for supercontinuum generation}

The experimental set-up is shown in Fig. 5. Our suspendedcore fiber is pumped with a high power laser source. The tunable central wavelength (from 3.5 to $11 \mu \mathrm{m}$ ) is delivered by a non-collinear optical parametric amplifier (NOPA) followed by a difference frequency generation (DFG) module. The NOPA is a TOPAS-Prime model, pumped by a chirped pulse amplified (CPA) Ti:sapphire system which delivers pulses centred at $790 \mathrm{~nm}$ with $3.2 \mathrm{~mJ}$ energy (100fs pulse duration) at $1 \mathrm{kHz}$ repetition rate. The DFG module delivers $65 \mathrm{fs}$ pulses with a maximum average power of $3.5 \mathrm{~mW}$ at $8.6 \mu \mathrm{m}$ (54 MW peak power). The infrared beam is focused in our $40 \mathrm{~mm}$-long chalcogenide fiber with a $\mathrm{ZnSe}$ objective $(f=6 \mathrm{~mm})$ to excite the fundamental mode. At the fiber output, the SC light is then collimated with a $\mathrm{ZnSe}$ objective $(f=12 \mathrm{~mm})$. The collimated beam is then focused into the slit of a monochromator with a gold coated parabolic mirror $(f=88.9 \mathrm{~mm})$. Our Newport Cornerstone TM130 1/8 $\mathrm{m}$ motorized monochromator includes a $150 \mathrm{l} / \mathrm{mm}$ diffraction grating used for the 3-13 $\mu \mathrm{m}$ range with a peak efficiency of $85 \%$ at the $5 \mu \mathrm{m}$ blaze wavelength. The output light is then focused onto a liquid nitrogen cooled $\mathrm{HgCdTe}$ detector (Hamamatsu P3412-02) with a gold coated mirror $(f=$ $50.8 \mathrm{~mm})$. We also made use of several long-pass filters (1.5, 2, 3, 5, 7 and $9 \mu \mathrm{m}$ ) inserted before the detector to avoid higher diffraction orders. Finally the full SC is reconstructed by gathering the filtered spectra.

\section{Results and discussion}

In a preliminary study [20], we studied SC generation in a similar suspended-core fiber (with a slightly different composition) with pumping wavelengths $(3.5$ and $5.5 \mu \mathrm{m})$ located in the normal dispersion regime $(D<0)$ or close to the fiber ZDW. Such wavelengths were first chosen to benefit from the high power delivered by the pump laser.

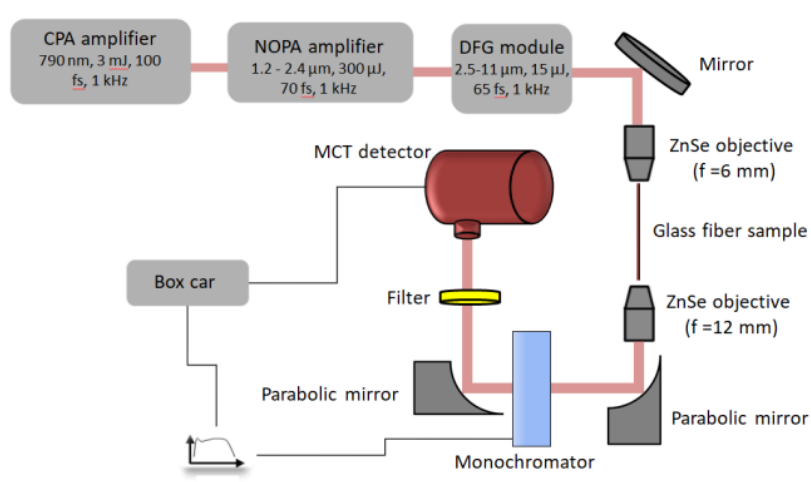

Figure 4. Experimental setup used for supercontinuum generation

However, we were not able to extend the SC bandwidth as far as in the step-index fiber configuration [20]. Here we present new experimental results, namely using pumping wavelengths centred at 7.5 and $8.6 \mu \mathrm{m}$. The corresponding SC spectra obtained in a 4-cm-long segment of $12 \mu \mathrm{m}$ suspended-core $\mathrm{Ge}_{20} \mathrm{Se}_{70} \mathrm{Te}_{10}$ fiber are shown in Figs. 6a and $6 \mathrm{c}$. We confirm that pumping the fiber further in the mid-IR allows now to push the mid-IR SC edge towards $\sim 13 \mu \mathrm{m}$. To date, this corresponds to the largest mid-IR extension of SC generation in a suspended-core optical fiber. We still not reach the fondamental long-wavelength transmission edge at $16 \mu \mathrm{m}$ (see Fig. 2) since we are limited by the strong absorption band centred at $12.7 \mu \mathrm{m}$ induced by a combination of different bonds involving oxygen. Moreover, our detection setup is not optimized for wavelengths above 12-13 $\mu \mathrm{m}$ (degraded efficiency of the grating and sensitivity of the MCT detector). In our experiments, the available average powers before the coupling objective are 5 and 3.5 $\mathrm{mW}$ at 7.5 and $8.6 \mu \mathrm{m}$ wavelength, respectively. The low average power and relatively degraded laser beam quality at such pumping wavelengths imply a weak coupling efficiency into our fiber, thus preventing the measurement of output average powers.

To further investigate SC generation (peak power involved, SC bandwidth limitations, etc.) we performed numerical simulations of the nonlinear pulse propagation in our fiber segment. Our modelling is based on the generalized nonlinear Schrödinger equation that includes the full 
dispersion curve (as shown in Fig. 4), both instantaneous Kerr and delayed Raman nonlinear responses, and the dispersion of nonlinearity [44].
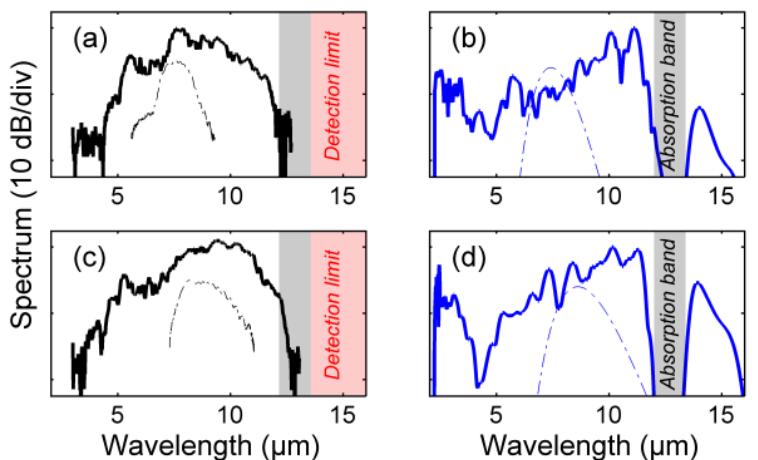

Figure 6. Experimental (left column) and numerical (right column) SC generation results (solid lines). Initial pump pulse spectra are indicated with dashed lines. The corresponding pumping wavelength is $7.5 \mu \mathrm{m}$ in subplots (a) and (b), and $8.6 \mu \mathrm{m}$ in subplots (c) and (d). The red areas denote the upper detection limit of our experimental setup, while gray areas are related with the location of the main absorption peak measured in Fig. 2.

The nonlinear fiber parameter was calculated above by means of the simulated effective mode area. For the Raman response function, we used an intermediate-broadening model using convolutions of Lorentzians and Gaussians adapted from spontaneous Raman scattering spectra given in Refs. [31][45]. Our simulations also include the losses of our GST glass measured in Fig. 2. We also considered 80-fs pump pulses, for both pumping wavelengths, which were deduced from the initial pump spectra shown in Figs. 6a and 6c. Numerical SC spectra obtained are depicted in Figs. 6b and $6 \mathrm{~d}$ for both pumping configurations. We carrefully took into account the same power ratio between the two pumping wavelengths as in experiments, in particular we used $270 \mathrm{~kW}$ peak power at $7.5 \mu \mathrm{m}$ and $190 \mathrm{~kW}$ peak power at $8.6 \mu \mathrm{m}$. We observe that our simulations reproduce qualitatively the main SC bandwidth in both cases. We also confirm the twooctave spanning mid-IR light source (from 3.25 to $13 \mu \mathrm{m}$ ) with $\sim 15 \mathrm{~nJ}$ femtosecond pulses at $8.6 \mu \mathrm{m}$. This main part of the SC is only related to the anomalous dispersion of our fiber, it then results from self-phase modulation and soliton dynamics. The main limitation of SC extension on the long wavelength edge remains the strong absorption band measured at $12.7 \mu \mathrm{m}$, however, we reveal that spectral broadening can go through this absorption and reach the multiphonon absorption in the mid-IR near $16 \mu \mathrm{m}$. This extra-broadening was not observed experimentally due to the limited bandwidth of our detection system. In additon, one can note that simulated SC spectra are also broader on the short-wavelength edge (up to $2 \mu \mathrm{m}$ ) in contrast to our measurements. As the SC light collection was optimized to highlight the main SC part and the long-wavelength edge, and as possible higher $\mathrm{OH}$ absorption occurs around $2.9 \mu \mathrm{m}$, all this could explain a lower efficiency to analyze the dispersive waves generated in the normal dispersion regime (i.e., the spectral band on the short wavelength edge). Such issues were also discussed in Ref. [18]. Finally, both recorded SC spectra strongly drop at $\sim 4.5 \mu \mathrm{m}$, thus evidencing the position of the $\mathrm{ZDW}$ in agreement with numerical predictions.

\section{Conclusion}

In conclusion, we demonstrated the fabrication and the application of a short segment of Ge-Se-Te glass-based suspended core fiber for mid-infrared supercontinuum generation that extends from 3.25 to $13 \mu \mathrm{m}$. Again this work clearly confirms the potential of these arsenic- and antimonyfree chalcogenide optical fibers for nonlinear optics in the mid-IR. To date, we have reported the largest mid-IR extension of SC generation in a suspended-core optical fiber. Moreover, our numerical simulations highlight the potential of such fibers to reach the multiphonon absorption edge of Se-rich GST glasses.This still requires optimization of our mid-IR detection system and an improved purification process as the one we used in [19]. In comparison to similar step-index GST fibers [20], the development of fibers with a smaller suspended core (higher nonlinearity and blue-shifted ZDW) could be suitable for compact SC sources when considering new femtosecond fiber lasers operating around 3-3.5 $\mu \mathrm{m}[46]$.

\section{Acknowledgements}

We acknowledge the financial support of the French Investissements d'Avenir program (ISITE-BFC ANR-15IDEX-0003, SCUVIRA project), the Council of the French Région Bourgogne Franche-Comté, and the European program FEDER, through the grant "Jeune Chercheur Entrepreneur" scheme.

\section{References}

[1] Zhao Z et al 2017 Laser Photonics Rev. 111700005

[2] Ferreira M F S et al 2017 J. Opt. 19083001

[3] Peters G P et al 2013 Nature Clim. Change 34

[4] Brilland L et al 2006 Opt. Express 141280

[5] Sanghera J S et al 2006 J. Optoelectron. Adv. Mater. 82148

[6] Dai S et al 2018 Appl. Sci. 8707

[7] Tao G et al 2015 Adv. Opt. Photonics 7379

[8] Petersen C R et al 2018 Infrared Phys. Technol. 91182

[9] Mouawad O et al 2014 Opt. Express 2223912

[10] Petersen C R et al 2014 Nat. Photonics 8830

[11] Wang Y et al 2017 Opt. Lett. 423458

[12] Si N et al 2018 Appl. Phys. A 124171

[13] Xue Z et al 2018 J. Lightwave Technol. 362416

[14] Tian Y et al 2018 IEEE Access 641093

[15] Li G et al 2018 J. Lightwave Technol. (early access)

[16] Cheng T et al 2014 Opt. Express 2223019 
[17] Møller U et al 2015 Opt. Express 233282

[18] Petersen C R et al 2016 Opt. Express 24749

[19] Wu B et al 2018 Opt. Mat. Express 81341

[20] Lemière A et al 2019 J. Opt. Soc. Am. B 36 A183

[21] Cheng T et al 2016 Opt. Lett. 412117

[22] Hudson D D et al 2017 Optica 41163

[23] Zhao Z et al 2016 Opt. Lett. 415222

[24] Jiao K et al 2019 Opt. Express 272036

[25] Kitchin K T 2001 Toxicol. Appl. Pharmacol. 172249

[26] https://ec.europa.eu/growth/sectors/chemicals/reach_en, "Reach," 2019. [Online]. Available: https://ec.europa.eu/growth/sectors/chemicals/reach_en

[27] Muir J and Cashman R 1967 J. Opt. Soc. Am. 571

[28] Maurugeon S et al 2011 Opt. Mater. 33660

[29] Maurugeon S et al 2010 J. Lightwave Technol. 283358

[30] Jiang X and Jha A 2015 Sens. Actuators B Chem. 206159

[31] Sun L et al 2016 Applied Physics A 122816

[32] Mouawad O et al 2014 Opt. Lett. 392684

[33] Snopatin G et al 2009 Inorg. Mater. 451439

[34] Shiryaev V S and Churbanov M F 2017 J. Non-Crystalline Solids 4751

[35] Petersen C R et al 2017 Opt. Express 2515336

[36] Churbanov M et al 2001 Optoelectron. Adv. Mater. 3341

[37] Troles J et al 2009 Opt. Mater. 32212

[38] Humbach O et al 1996 J. Non-Crystalline Solids 20319

[39] El-Amraoui M et al 2010 Opt. Express 184547

[40] Savelii I et al 2012 Opt. Express 2027083

[41] Aio L, Efimov A and Kokorina V 1978 J. Non-Crystalline Solids 27299

[42] Mittal V, Wilkinson J S and Murugan G S 2014 Proc. SPIE 8988 89881A

[43] Boudebs G et al 2001 Opt. Commun. 199425

[44] Dudley J M, Genty G and Coen S 2006 Rev. Mod. Phys. 78 1135

[45] Moharram A H et al 2010 J. Appl. Phys. 108073505

[46] http://www.femtum.com/en/products/ultrafast-laser/. 